\title{
Ontogenetic body-mass scaling of nitrogen excretion relates to body surface area in
} diverse pelagic invertebrates

Hirst, Andrew G.; Lilley, M.K.S.; Glazier, D.S.; Atkinson, D.

Published in:

Limnology and Oceanography

Link to article, DOI:

10.1002/Ino.10396

Publication date:

2017

Document Version

Publisher's PDF, also known as Version of record

Link back to DTU Orbit

Citation (APA):

Hirst, A. G., Lilley, M. K. S., Glazier, D. S., \& Atkinson, D. (2017). Ontogenetic body-mass scaling of nitrogen excretion relates to body surface area in diverse pelagic invertebrates. Limnology and Oceanography, 62(1), 311-319. https://doi.org/10.1002/lno.10396

\section{General rights}

Copyright and moral rights for the publications made accessible in the public portal are retained by the authors and/or other copyright owners and it is a condition of accessing publications that users recognise and abide by the legal requirements associated with these rights.

- Users may download and print one copy of any publication from the public portal for the purpose of private study or research.

- You may not further distribute the material or use it for any profit-making activity or commercial gain

- You may freely distribute the URL identifying the publication in the public portal 


\title{
Ontogenetic body-mass scaling of nitrogen excretion relates to body surface area in diverse pelagic invertebrates
}

\author{
A. G. Hirst, ${ }^{1,2 *}$ M. K. S. Lilley, ${ }^{1}$ D. S. Glazier, ${ }^{3}$ D. Atkinson ${ }^{4}$ \\ ${ }^{1}$ School of Biological and Chemical Sciences, Queen Mary University of London, London, United Kingdom \\ ${ }^{2}$ Centre for Ocean Life, National Institute for Aquatic Resources, Technical University of Denmark, Charlottenlund, \\ Denmark \\ ${ }^{3}$ Department of Biology, Juniata College, Huntingdon, Pennsylvania \\ ${ }^{4}$ Institute of Integrative Biology, University of Liverpool, Liverpool, United Kingdom
}

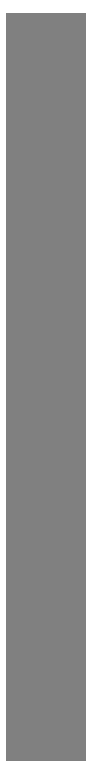

\begin{abstract}
Many physiological and ecological processes depend on body size and the supply of limiting nutrients. Hence, it is important to derive quantitative predictions based on a mechanistic understanding of the influence of body size on metabolic rate and on the ratios of consumed to excreted elements. Among diverse pelagic invertebrates that change shape during ontogeny, recent analysis has demonstrated a significant positive correlation between the body-mass allometry of respiration rates (measured as the ontogenetic body mass-scaling exponent $\left.b_{R}\right)$ and the allometry of body surface area $\left(b_{A}\right.$, as predicted from body-shape changes using a Euclidean model). As many pelagic invertebrates use a large portion of their external body surface for both resource uptake and waste excretion, we predicted that body-mass scaling exponents for rates of excretion of soluble $\mathrm{N}\left(b_{N}\right)$ should also then relate to the degree of body-shape change during growth. We tested this hypothesis using literature data on $b_{N}$ for 39 species of pelagic invertebrates across five different phyla, and find strong support: $b_{N}$ is significantly positively correlated with predicted $b_{A}$, whilst also co-varying with $b_{R}$. Intraspecific differences between $b_{N}$ and $b_{R}$ values reveal ontogenetic shifts in the ratio of $\mathrm{O}_{2}$-consumed to N-excreted. We suggest that a variety of factors, including adaptive developmental shifts in the relative anabolism and catabolism of proteins and lipids, may cause these shifts in consumption-excretion ratios. Diverse pelagic invertebrates that dominate vast open water ecosystems falsify the predictions of general metabolic scaling theories built upon resource-transport networks, but support predictions of surfacearea dependent theory.
\end{abstract}

Metabolism is central to the physiology and ecology of all organisms. Hence it is crucial to understand what controls metabolic variability. One major predictive variable is body size, but how and why metabolic rates scale with body mass has been debated for over 80 years (Kleiber 1932, 1961; Schmidt-Nielsen 1984; Glazier 2005, 2014a; White and Kearney 2014). Major competing theories that predict metabolic scaling differ according to whether transport of materials depends primarily on external exchange surfaces, e.g. the integument or gills (Surface Area or SA theory) (Rubner 1883; Okie 2013), or on the properties of internal transport networks, e.g. vascular systems (Resource-Transport Network

*Correspondence: a.g.hirst@qmul.ac.uk

Additional Supporting Information may be found in the online version of this article. or RTN theory) (West et al. 1999; Savage et al. 2008; Banavar et al. 2010). SA theory includes not only Rubner's (1883) surface law, which focuses specifically on metabolic heat loss in endotherms, but also other exchanges through surfaces, including the uptake of energy and materials and the release of metabolic wastes through the surfaces of many ectothermic organisms (Glazier 2014b; Hirst et al. 2014). SA theory may therefore be considered to apply to taxa that are either endotherms (where SA-related heat loss is important), or ectotherms that have permeable surfaces across which fluxes of respiratory gases, nutrients, and (or) wastes can occur (Glazier 2014a). When bodies grow in equal proportions in all three dimensions (isomorphic enlargement), surface area should scale with body volume with an exponent of $2 / 3$. Consequently, SA theory predicts that metabolic rate should also have a volume-scaling exponent of $2 / 3$. Furthermore, assuming constant body-mass density, the body-mass scaling 
Initial Shape
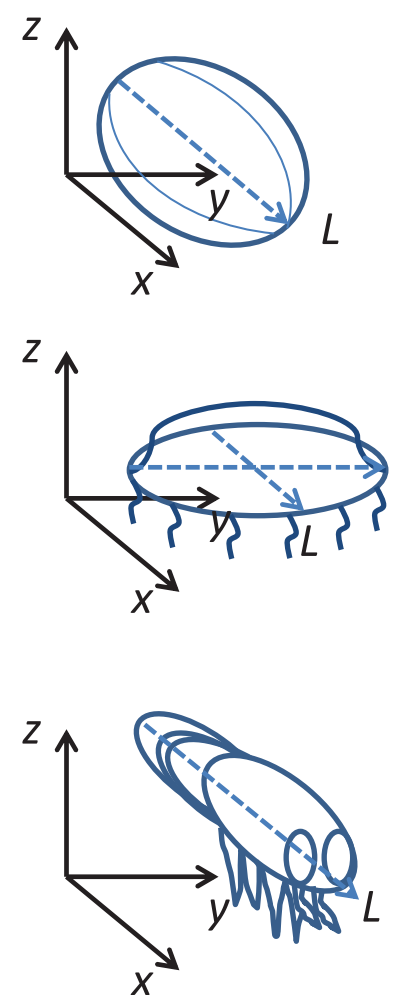

Final Shape

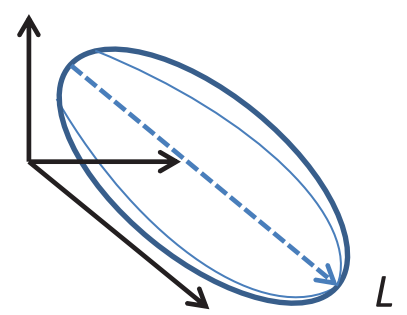

Mass $\propto L^{1} \quad$ Surface $_{\text {Mass }^{1}}$

$b_{L}=1$

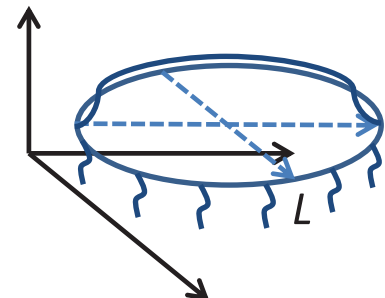

$\begin{array}{ll}\text { Mass } \propto L^{2} & \text { Surface } \\ b_{L}=2 & \text { Area } \text { Mass }^{1}\end{array}$
A ctenophore enlarging in 1 dimension $(x)$ along the major body axis (L); the body becomes more elongate with growth
A hydromedusa enlarging in 2 dimensions ( $x$ and $y$ ) along the major body axis (L); the body becomes flatter with growth

Fig. 1. Three illustrative examples of shape changes in organisms over ontogeny, with associated exponents from mass-length $\left(b_{L}\right)$ and surface areamass $\left(b_{A}\right)$ regressions. $L$ describes the major body axis and is given by the dashed arrow. The left-hand column indicates the initial shape, the righthand column the final shape. The three dimensions are denoted as $x, y$, and $z$. The upper example describes a ctenophore elongating along its oralaboral axis $(L)$, whilst other axes do not enlarge. In this example $b_{L}$ and $b_{A}$ both approach 1 . The middle example describes a medusa which elongates along its bell diameter $(L)$. As the organism is radially symmetrical in the $x-y$ plane throughout ontogeny, size increases along two dimensions ( $x$ and y) equally, but in this example with no increase in the bell thickness $(z)$. In this example $b_{L}$ and $b_{A}$ approach 2 and 1 , respectively. The lower example describes an amphipod which enlarges isomorphically, i.e. proportionately equally in all three dimensions $(x, y$, and $z)$, hence with no shape change: here $b_{L}$ and $b_{A}$ approach 3 and $2 / 3$, respectively. These examples assume that mass-density does not change over ontogeny, and hence mass $\propto$ volume. [Color figure can be viewed in the online issue, which is available at wileyonlinelibrary.com.]

exponent for metabolic (respiration) rate (henceforth denoted as $b_{R}$ ) should be $2 / 3$ as well. By comparison, RTN theory typically predicts $b_{R}$ to be either $2 / 3$ (Banavar et al. 2010; Dodds 2010) or $3 / 4$ (West et al. 1997, 1999; Banavar et al. 2010), depending on the physical properties of the transport network (Savage et al. 2008; Price et al. 2012). Therefore, the scaling exponents predicted by SA and RTN theory are very similar, and thus difficult to distinguish with empirical tests. However, SA and RTN theories make opposite predictions about how body-shape changes should affect metabolic scaling (Hirst et al. 2014; Glazier et al. 2015), thus providing a way to test their relative validity.

By applying simple Euclidean geometry to smooth bodies one can predict the scaling exponent of surface area with body mass during ontogeny $\left(b_{A}\right)$ from the ontogenetic scaling exponent of body mass with body length, $b_{L}$ (see Fig. 1; for further details also see Figs. 1 and 2 in Hirst et al. 2014), and how $b_{A}$ should vary with different degrees of body-shape change. This theory predicts that increased elongation or flattening of body shape will result in $b_{A}$ being between $2 / 3$ and 1 (Okie 2013; Hirst et al. 2014). Assuming that metabolic rate is proportional to the rate of exchange of energy and materials across the total body-surface area, then SA theory predicts that increasing elongation or flattening of an organism's body shape during growth should result in $b_{R}$ being $>^{2} / 3$. In the extreme case, where growth from a minute size occurs by elongation in only one dimension along the longest axis (i.e., body length increases without any change in width or depth, and thus $b_{L}=1$ ), SA theory predicts that $b_{R}$ $\sim 1$ (Okie 2013; Hirst et al. 2014), whereas RTN theory predicts that $b_{R} \sim 0$ (Dodds 2010), $1 / 4$ (Banavar et al. 2010; Hirst et al. 2014), or $1 / 2$ (West et al. 1999), depending on properties of the resource-transport network. As another extreme example, when growth occurs only along the two longest dimensions (e.g., length and width increase, without any change in depth, and hence the body becomes increasingly 


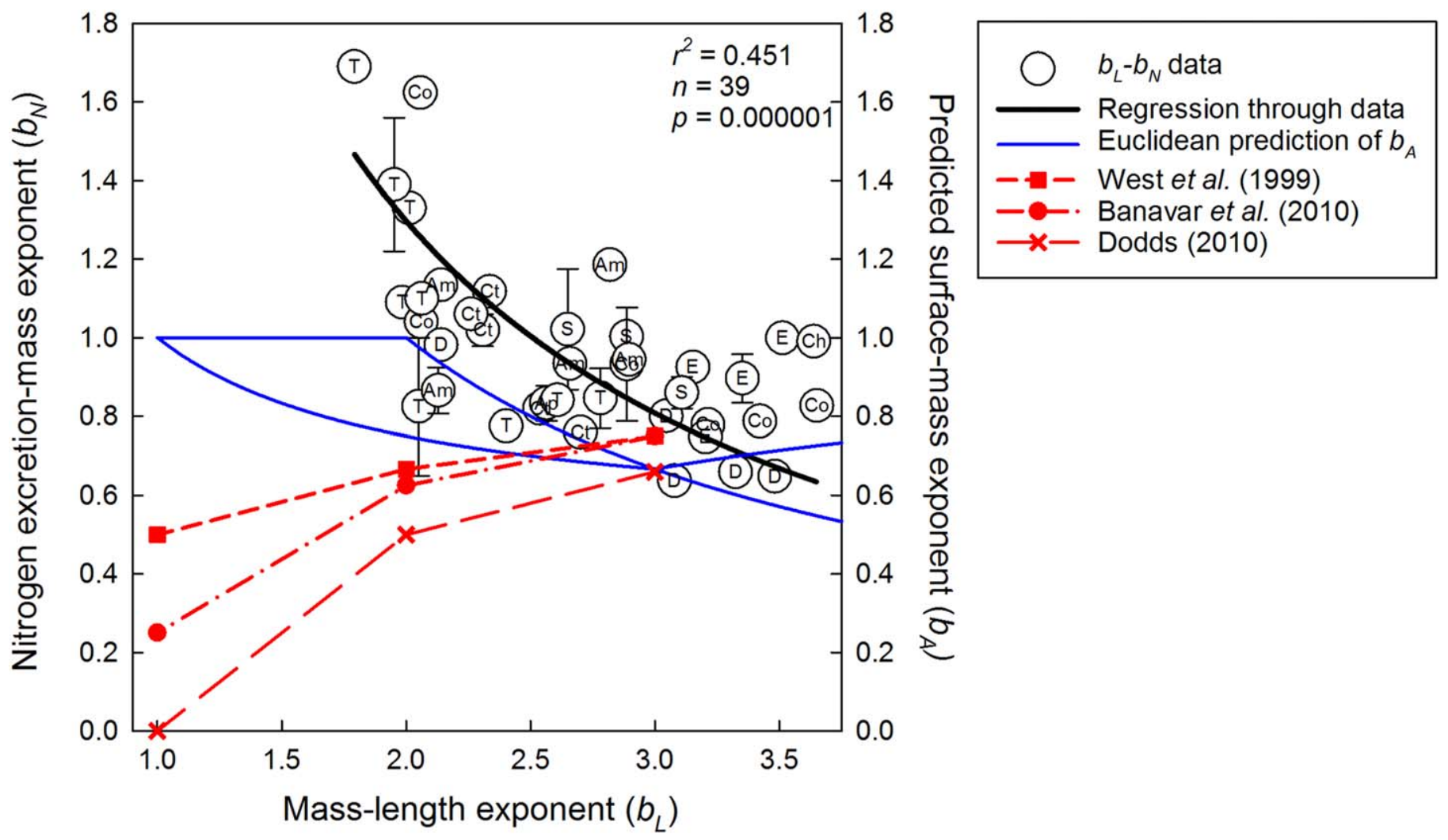

Fig. 2. Body-mass-scaling exponents for nitrogen excretion $\left(b_{N}\right)$ in relation to body-mass to length exponents $\left(b_{L}\right)$ during ontogeny in diverse pelagic invertebrates. Each point represents a single species with error bars $( \pm \mathrm{SE})$ showing the variation in values between studies. The RMA regression of $b_{N}$ vs. $1 / b_{L}$ data is depicted by a solid line and is significant $\left(b_{N}=2.93\left(1 / b_{L}\right)-0.169 ; r^{2}=0.451 ; p=0.000001\right)$. The envelope enclosed by the blue lines shows the range of surface area-mass scaling exponents $\left(b_{A}\right)$ predicted by a Euclidean model of body-shape change (see Hirst et al. 2014 for model details). Red lines depict the predictions of the resource-transport network models of West et al. (1999), Banavar et al. (2010), and Dodds (2010). Letters within each data point denote the taxonomic group to which each species belong: A, appendicularians; Am, amphipods; D, decapods; E, euphausiids; C, chaetognaths; Co, copepods; Ct, ctenophores; S, scyphozoans; and T, thaliaceans.

flattened and thus $b_{L}=2$ ), SA theory predicts that $b_{R} \sim 1$ (Okie 2013; Hirst et al. 2014), whereas RTN models predict an exponent of $\sim 1 / 2$ (Dodds 2010), 5/8 (Banavar et al. 2010; Hirst et al. 2014) or $2 / 3$ (West et al. 1999), depending again on network geometry and dynamics. Pelagic (open-water) invertebrates present excellent opportunities to test the competing predictions of SA and RTN theories, as many fulfil the assumptions of the SA theory, utilizing large portions of their general body surface for exchange of materials, such as respiratory gases (Graham 1988; Pirow et al. 1999). These animals also show a great diversity in the degree of shape shifting during ontogeny (Hirst 2012), which helps greatly in distinguishing between predictions of SA and RTN theories (Hirst et al. 2014; Glazier et al. 2015).

Recent tests of SA and RTN theories applied to pelagic invertebrates during ontogeny have demonstrated a significant positive correlation between $b_{R}$ and degree of body flattening or elongation (Hirst et al. 2014; Glazier et al. 2015), hence supporting predictions of SA theory, whilst contradicting those of various RTN models (West et al. 1999; Banavar et al. 2010). Respiration (oxygen consumption) rate is a proxy for aerobic metabolic rate, which involves many complex life-sustaining biochemical pathways and energyproducing reactions. Other important outcomes of metabolism include the production of wastes, including $\mathrm{CO}_{2}$ and nitrogenous compounds, such as ammonia $\left(\mathrm{NH}_{3}\right)$ and ammonium ions $\left(\mathrm{NH}_{4}^{+}\right)$(Bidigare 1983; Wright 1995). These terminal metabolic products come from the breakdown and utilization of proteins, carbohydrates and amino acids involved in growth and body-tissue maintenance. Examining the ontogenetic body-mass scaling of waste production and its relation to the scaling of surface area and respiration rate may give us valuable insight into how various components of metabolism (in particular oxygen utilization and nitrogen excretion) scale with body mass, which is little understood (see Ikeda 1985; Glazier 2014a). Since many pelagic animals apparently rely on significant proportions of their external body surface for oxygen uptake (Hirst et al. 2014; Glazier et al. 2015), it seems reasonable to suppose that often they also do so for the efflux of soluble nitrogenous wastes, such 
as ammonia (Hill et al. 2012). The locations on the body at which $\mathrm{N}$ excretion occurs vary between taxa. In many gelatinous and semi-gelatinous taxa waste excretion is believed to be widely dispersed across the body. By contrast, in some arthropods, it occurs at the antennary glands and gills. However, in copepods and potentially other pelagic crustaceans, the sites of ammonia excretion are more dispersed, and specifically include regions of gas and osmoregulatory exchange (D. Weihrauch pers. comm.). For example, the swimming legs of the copepod Eurytemora affinis have recently been found to be the location of osmoregulatory tissues (Johnson et al. 2014), and are therefore likely sites for ammonia excretion as well. The addition of leg pairs during ontogeny occurs with concurrent body elongation, and therefore the total area of excretion sites may be expected to correlate with body length and surface area during body elongation. Examining body-mass scaling (or allometry) of N-excretion and comparing this against the allometry of respiration will therefore help further elucidate important mechanisms that influence oxygen and nitrogen fluxes. Furthermore, excreted nitrogenous wastes are used as nutrients that support many ecologically important processes. For example, the availability of fixed nitrogen can limit photosynthesis by algae in many aquatic ecosystems (Elser et al. 2007). Therefore, analyses of the body-mass scaling of soluble N-products not only offers a valuable opportunity to test general metabolic scaling theories, but also may provide useful data for modelling the quantitative dynamics of nutrient recycling in aquatic ecosystems. Thus, the major aims of this study are (1) to test whether body-mass scaling of N-excretion during the ontogeny of pelagic invertebrates follows predictions based on SA theory, such that $b_{N}$ is negatively related to $b_{L}$, (2) to test alternative hypotheses, that body-mass scaling of $\mathrm{N}$ excretion follows predictions based on RTN theory, such that $b_{N}$ is positively related to $b_{L}$, and (3) to determine the degree to which $b_{R}$ and $b_{N}$ differ within species, and hence the degree to which the ratio of $\mathrm{O}_{2}$-respired to $\mathrm{N}$-excreted varies over ontogeny.

\section{Materials and methods}

We obtained estimates of the scaling of N-excretion with body mass across ontogeny $\left(b_{N}\right)$ of marine and freshwater pelagic invertebrates by searching the literature for regressions between $\log _{10}$ excretion rate vs. $\log _{10}$ body mass at controlled constant temperatures. Sources were identified during an exhaustive search of the literature: this included keyword searches in ISI Web of Knowledge and Google Scholar. We followed leads from citations in publications and by contact with many experts on specific taxa to ensure data had not been missed. Nitrogen excretion is measured using a range of methodologies (see Table S2, Supporting Information), including the measurement of ammonia $\left(\mathrm{NH}_{3}\right)$, ammonium ions $\left(\mathrm{NH}_{4}^{+}\right)$, and the nitrogen contribution to various nitrogenous compounds ( $\left.\mathrm{N}, \mathrm{N}-\mathrm{NH}_{3}, \mathrm{~N}-\mathrm{NH}_{4}^{+}\right)$, usually in units of $\mu \mathrm{g}, \mu \mathrm{mol}$, or $\mu \mathrm{g}$-atoms measured per individual overtime. These various forms of excretion were converted into equivalent units of moles of $\mathrm{N}$. We also collected studies that provided estimates of the scaling of both $\mathrm{N}$-excretion $\left(b_{N}\right)$ and respiration $\left(b_{R}\right)$ during the ontogeny of single species: these paired scaling exponents were converted to molar units for comparison. All experimental animals had been recently collected, or well-fed in a laboratory environment, thereby excluding data from studies where animals had undergone long-term starvation. All allometric (log-log) relationships obtained for our analyses were based on OLS. Literature values of scaling exponents based on Reduced Major Axis (RMA) regressions (also referred to as Geometric Mean regressions) were converted to OLS equivalents using the formula $b_{\mathrm{RMA}}=b_{\mathrm{OLS}} r$, where $r$ is the correlation coefficient. Data sets were screened to remove values of scaling exponents that were less reliable, as defined by regressions with $r<0.8$. Benthic (bottom-dwelling) species were excluded because many of them have largely impermeable integuments or body coverings (e.g., shells and exoskeletons), hence less association between body surface and material exchange, and they may experience markedly different size-scaling of trophic interactions than pelagic species (Pawar et al. 2012).

Ontogenetic shape change was characterized by a single statistic: the scaling exponent $\left(b_{L}\right)$ from regressions relating $\log _{10}$ mass to $\log _{10}$ length. We expanded the $b_{L}$ dataset of Hirst (2012), specifically adding species that would enable us to relate $b_{N}$ exponents to the degree of body-shape shifting, and followed his data screening procedure, excluding less reliable regression estimates (i.e., where reported correlation coefficients $r$ were $<0.8$ ). To avoid systematic over-representation of commonly measured species, mean scaling exponents were calculated for species. Values of $b_{A}$ were predicted from $b_{L}$ using the Euclidean model presented in Hirst et al. (2014). Briefly, assuming smooth surfaces, this model predicts that $b_{A}$ will equal $2 / 3$ when $b_{L}$ equals 3 (resulting from equally proportional isomorphic growth in all three dimensions), but $b_{A}$ will approach 1 as $b_{L}$ approaches either 1 (resulting from elongation or growth chiefly along the longest dimension) or 2 (resulting from shape flattening arising from growth chiefly along the longest two dimensions) (Fig. 1). Since the Euclidean surface-area model of Hirst et al. (2014) predicts linear relations between metabolic scaling exponents ( $b_{N}$ in this case) and $1 / b_{L}$, we performed RMA regressions between these two parameters using software from Bohonak and van der Linde (2004). These relationships were examined for all of the species-specific data, as well as across species within each of the phyla represented. Minitab v12 statistical software was used to perform the Wilcoxon signed rank test. As well as examining the relationship among species mean $b_{N}$ and $1 / b_{L}$ values, we also controlled for taxonomic affiliation and rank by running a simple linear mixed-effects model using package nlme in $\mathrm{R}$, which incorporated taxonomic ranks (species, 


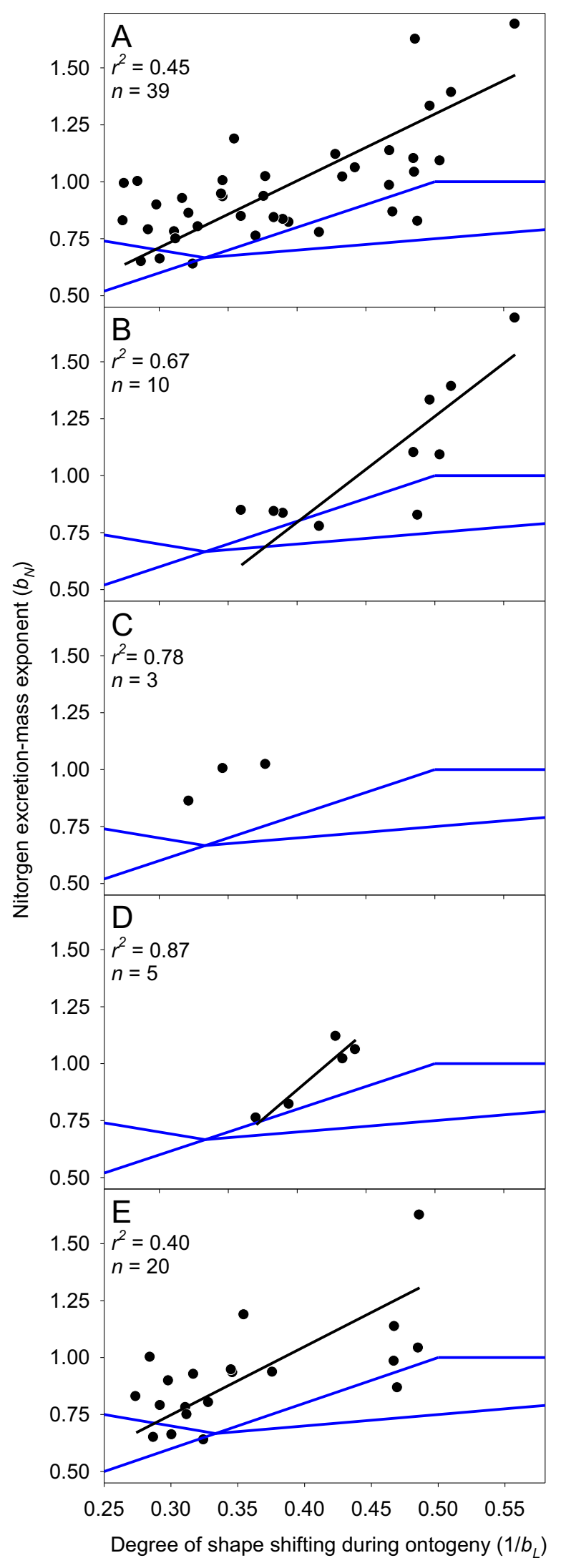

Fig. 3. genus, family, order, class, phylum) as nested hierarchical random effects on the intercept (van de Pol and Wright 2009).

\section{Results}

To test whether body-mass scaling of N-excretion during the ontogeny of pelagic invertebrates follows predictions based on SA or RTN models, we obtained N-excretion scaling exponents that fulfilled our screening criteria from 75 regressions describing $b_{N}$ in 39 pelagic species (37 marine and 2 freshwater) across five phyla (Tables S1-S3, Supporting Information). Mass-length exponents $\left(b_{L}\right)$ for 34 of these species were obtained from Hirst et al. (2014), with additional data obtained from other published sources (Table S3, Supporting Information).

We found that as $b_{L}$ values decrease, $b_{N}$ values increase, i.e. there was a significant increase in species-specific $b_{N}$ with increasing body elongation or shape flattening (as shown by the regression through the data given by the black line in Fig. 2). The direction of this trend supports SA theory, which predicts negative slopes for both body elongation and shape flattening (the lower and upper lines of the blue envelope in Fig. 2). The slope of the RMA regression between $b_{N}$ and $1 / b_{L}$ is 2.93 with $99 \%$ confidence intervals ranging between 2.21 and 3.66, neither of which overlap zero or the predicted negative slopes predicted by RTN models (red lines, Fig. 2). After controlling for taxonomic affiliation and rank, there is still a significant positive relationship between $b_{N}$ and $1 / b_{L}$ across species $\left(t_{11}=5.32, p<0.001\right.$; see Supporting Information Table S5 in our Supporting Information for the coefficient table), hence corroborating findings from the regression analysis in Figure 2. Furthermore, RMA regressions between $b_{N}$ and $1 / b_{L}$ are significant across species within each of the phyla with $\mathrm{n}>3$ species: Chordata, Ctenophora, and Arthropoda (Fig. 3). Most $b_{N}$ values were greater than the predicted scaling exponents for surface-area in relation to body-mass $\left(b_{A}\right)$ (area contained within the blue lines, Figs. 2 and 3).

Species-specific $b_{N}$ values were significantly positively related to $b_{R}$ values (Fig. 4 ). While some species showed much steeper scaling of respiration than N-excretion, others showed much steeper N-excretion scaling. The ratio of moles of dioxygen consumed to nitrogen excreted $\left(\mathrm{O}_{2}: \mathrm{N}\right)$ over ontogeny for single

Fig. 3. Relationships between mass-scaling exponent for nitrogen excretion rate during ontogeny $\left(b_{N}\right)$ and change in body shape, $1 / b_{L}$ for individual species of pelagic invertebrates. Each species is represented by a black circle. RMA regression lines, in black, are drawn through significant trends only $(p<0.05)$. The envelope enclosed by the blue lines shows the predictions for Euclidean surface-area increase. (a) All data (slope $\pm 95 \%$ Cl: $2.93 \pm 0.73$ ), (b) Chordata (slope $\pm 95 \% \mathrm{Cl}$ : $4.65 \pm 2.18$ ), (c) Cnidaria (ns), (d) Ctenophora (slope $\pm 95 \% \mathrm{Cl}$ : $5.16 \pm 3.40$ ), (e) Arthropoda (slope $\pm 95 \%$ Cl: $3.00 \pm 1.15$ ). The observed positive trends through the empirical data are opposite to the negative slopes predicted by resource transport network models (see Fig. 2). 


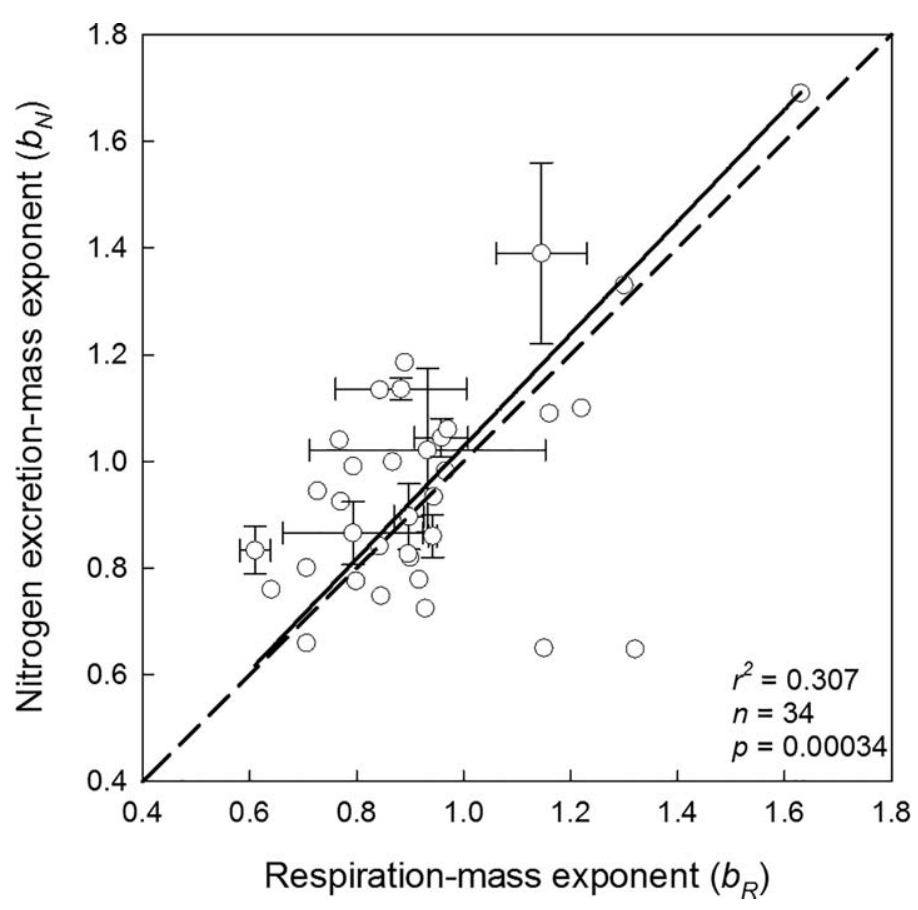

Fig. 4. Comparisons between the ontogenetic scaling exponents for $\mathrm{N}$ excretion $\left(b_{N}\right)$ and for $\mathrm{O}_{2}$-consumption $\left(b_{R}\right)$ across individual species of diverse pelagic invertebrates. Error bars $( \pm \mathrm{SE})$ are derived from $b_{R}$ or $b_{N}$ estimates for single species between studies. The solid line depicts the RMA regression of $b_{N}$ against $b_{R}$ values $\left(b_{N}=1.052\left(b_{R}\right)-0.0235\right.$; $\left.r^{2}=0.307 ; p=0.00034\right)$. The dashed line indicates a 1:1 relationship.

species for which data were available are presented in Figure 5. These ratios are useful for revealing the relative rates of different metabolic processes (see Discussion section). A Wilcoxon signed rank test of the allometric slopes of molar $\mathrm{O}_{2}: \mathrm{N}$ ratios during ontogeny revealed no significant difference in frequency of positive and negative slopes ( $p=0.501$; Fig. 5$)$. Of the 24 slopes, 12 species had positive slopes (median $=0.0885$; range $=0.0008-0.6718$ ) and 12 had negative slopes (median $=$ -0.1299 ; range $=-0.67$ to -0.0219 ).

\section{Discussion}

The mass scaling of N-excretion, $b_{N}$, is highly significantly correlated with the degree of body-shape change (e.g., flattening or elongation) over ontogeny, as described by $b_{L}$, across diverse pelagic invertebrate species (Fig. 2), and across species within 3 of the 4 phyla with sufficient data (Fig. 3). This correlation, based on $b_{N}$ values, is similar to that observed for respiration-mass scaling $\left(b_{R}\right)$ values (Hirst et al. 2014; Glazier et al. 2015), which together provide strong support for a functional linkage between metabolic scaling and SA-related fluxes of metabolic resources and wastes in pelagic invertebrates. By contrast, the observed positive relationships between $b_{N}$ and $1 / b_{L}$ contradict RTN models that predict opposite, negative relationships, i.e. they predict a decline in the allometric slope for excretion rates when body shape becomes more elongated or flattened during ontogeny (West et al. 1999; Banavar et al. 2010; Dodds 2010). The significant relationships occurred despite variation in diet affecting the scaling of N-excretion with body mass $\left(b_{N}\right)$ (Capuzzo and Lancaster 1979).

Individual $b_{N}$ values tend to be greater than the $b_{A}$ values predicted using simple Euclidean geometry (see Hirst et al. 2014). As a result, the regression lines for species-specific $b_{N}$ vs. $1 / b_{L}$ values lie substantially above the envelope of predicted $b_{A}$ values (Figs. 2 and 3). These higher allometric slopes for N-excretion than for Euclidean surface area are paralleled by the higher observed values of $b_{R}$ than those of $b_{A}$ (Hirst et al. 2014; Glazier et al. 2015). These differences between metabolic allometry and Euclidean surface area allometry may at least partly result from Euclidean geometry (based on smooth surfaces) underestimating the changes in actual surface areas. Such an underestimate has been detected in three species for which there are measurements of surface enlargement over ontogeny (Hirst et al. 2014). The $b_{A}$ values for actual surface areas may thus be higher than the prediction (and closer to observed $b_{N}$ and $b_{R}$ values). The offset may in part be due to the fact that the Euclidean surface area model does not account for the development of increasingly convoluted body surfaces, including the addition of frills and appendages, during ontogeny (see Hirst et al. 2014).

The significant regression of $b_{N}$ against $b_{R}$ values (Fig. 4) contained scatter around the 1:1 line. Although some species show steeper scaling of aerobic respiration than of $\mathrm{N}$ excretion, others showed the reverse. The differential scaling of these processes highlight ontogenetic shifts in the ratio of consumption of $\mathrm{O}_{2}$ to the excretion of $\mathrm{N}$ over ontogeny, such that when $b_{R}$ exceeds $b_{N}$ the $\mathrm{O}_{2}: \mathrm{N}$ ratio must increase during development, whereas when $b_{N}$ exceeds $b_{R}$ the ratio must decline.

The $\mathrm{O}_{2}: \mathrm{N}$ ratio is generally considered to be a good indicator of the biochemical composition of metabolized food (e.g., Mayzaud and Conover 1988). High ratios reflect an equal catabolism of lipids and proteins, or nearly so, whereas lower ratios reflect a higher relative use of proteins (Mayzaud 1973; Ikeda 1974). Most of the pelagic invertebrates analyzed in our study exhibited $\mathrm{O}_{2}: \mathrm{N}$ molar ratios ranging from low values near 3 , suggesting an emphasis on protein catabolism, to relatively high values near 60 , suggesting nearly equal proportions of protein and lipid being utilized (Mayzaud and Conover 1988). Negative scaling exponents for the $\mathrm{O}_{2}: \mathrm{N}$ ratio suggest ontogenetic shifts toward a more proteindominated catabolism with increasing size, while positive slopes indicate the reverse (Fig. 5). Both occur in pelagic species, with neither predominating. Long-term starvation and an unbalanced diet can affect the $\mathrm{O}_{2}: \mathrm{N}$ ratio (Mayzaud and Conover 1988), but these factors are unlikely to have caused the ontogenetic shifts that we have observed, because we only considered fed laboratory animals or those collected 


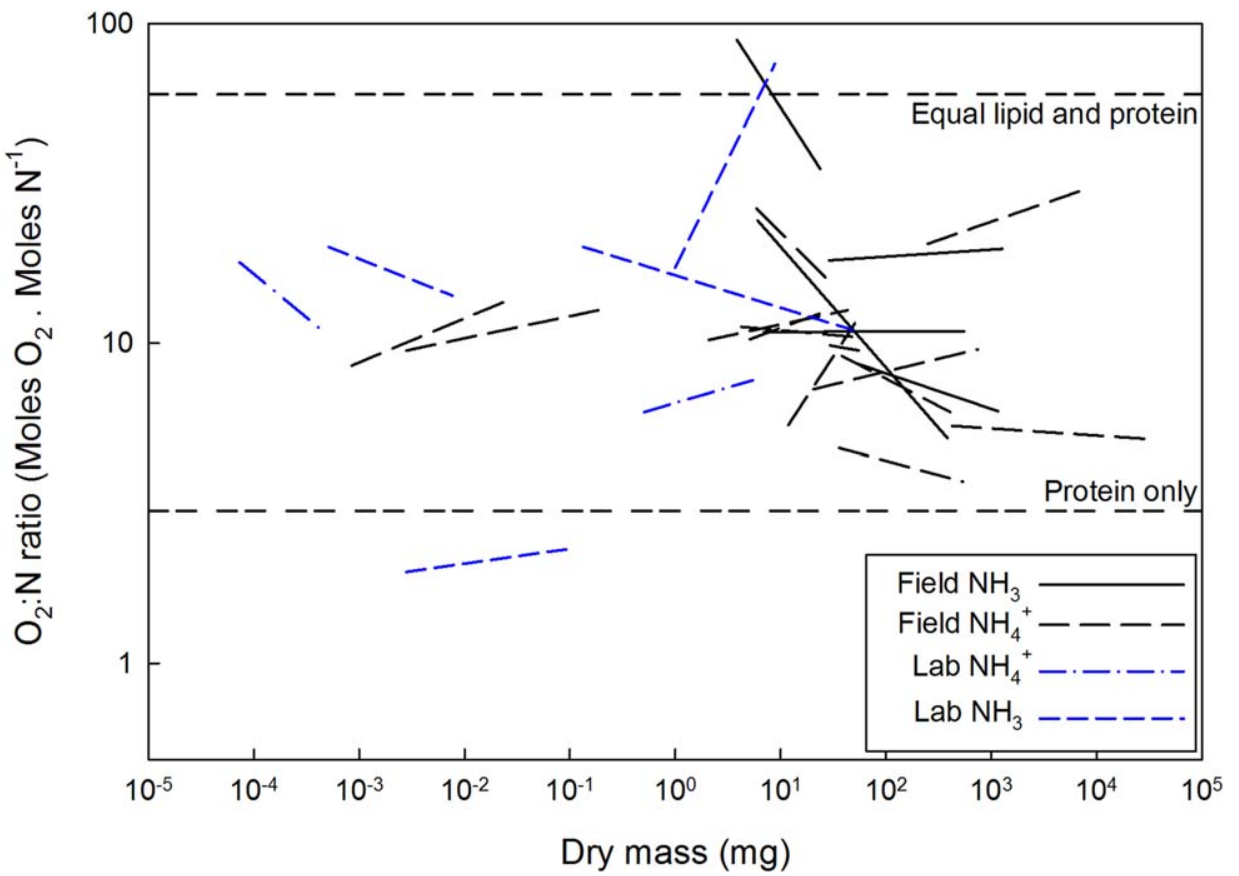

Fig. 5. Molar ratios of dioxygen consumed to nitrogen excreted $\left(\mathrm{O}_{2}: \mathrm{N}\right)$ vs. body mass in pelagic invertebrate species $(n=24)$. Each line represents data from a single species as given within a single study, in which both respiration and excretion had been determined and $r \geq 0.8$. Results are divided between those in which excretion was measured as ammonia $\left(\mathrm{NH}_{3}\right)$ or ammonium ions $\left(\mathrm{NH}_{4}^{+}\right)$, and between laboratory-cultured or field-collected animals (see key). Dashed horizontal lines represent the molar $\mathrm{O}_{2}: \mathrm{N}$ ratios corresponding to catabolism based entirely on protein (3), vs. equal catabolism of protein and lipid (60) (after Mayzaud and Conover 1988). [Color figure can be viewed in the online issue, which is available at wileyonlinelibrary.com.]

from nature and incubated for short time periods. In addition, ontogenetic shifts in the $\mathrm{O}_{2}: \mathrm{N}$ ratio are unlikely to be the result of changes in diet during growth because laboratory-kept animals fed the same diet throughout their ontogeny still exhibit these shifts (Fig. 5).

We suggest that strong ontogenetic shifts in the $\mathrm{O}_{2}: \mathrm{N}$ ratio observed in some pelagic invertebrates may be related to adaptive developmental change in resource allocation priority between structural growth, somatic storage, reproduction, and other vital activities. Ontogenetic changes in the relative rates of structural growth and body-storage deposition may affect the $\mathrm{O}_{2}: \mathrm{N}$ ratio because of associated developmental shifts in the relative magnitudes of protein and lipid accumulation (anabolism) and breakdown (catabolism). For example, an ontogenetic decline in the $\mathrm{O}_{2}: \mathrm{N}$ ratio may result from decrease in the rate of anabolic structural (protein) growth relative to that for body (lipid) storage: i.e., specifically decreasing protein anabolism (supporting growth) relative to its catabolism, and decreasing lipid catabolism (energizing growth) relative to its anabolism during ontogeny. By contrast, an ontogenetic increase in the $\mathrm{O}_{2}: \mathrm{N}$ ratio may result from an increase in the rate of anabolic structural growth relative to that for body storage: i.e., specifically an increase in protein anabolism relative to catabolism, and of lipid catabolism relative to anabolism. Variation in the ontogeny of the $\mathrm{O}_{2}: \mathrm{N}$ ratio may indicate fundamental life-history differences among pelagic invertebrate species, a hypothesis requiring testing. Ontogenetic variation in $\mathrm{O}_{2}: \mathrm{N}$ ratios may not only provide insight into the developmental metabolism of pelagic animals, but also the stoichiometry of ecological systems, including, for example, seasonal changes in N-budgets that are linked to pelagic animal life cycles. Nitrogen availability often limits the rate of photosynthesis in marine and some freshwater ecosystems (James et al. 2003; Moore et al. 2013), and low availability of $\mathrm{N}$ can lead to high $\mathrm{C}: \mathrm{N}$ ratios in algae, making them a poorer quality food for algivores (Hessen et al. 2007).

Shape-shifting $\left(b_{L}\right)$ explains a similar degree of variability in $b_{N}\left(r^{2}=0.45\right.$; data in Fig. 2$)$ and $b_{R}$ values $\left(r^{2}=0.37\right.$; data from Hirst et al. 2014). This may be somewhat surprising because oxygen consumption is generally regarded as a more direct and reliable measure of overall aerobic metabolism, whereas excretion rates may vary more with the composition of consumed prey and specific biochemical needs for tissue growth, repair and energy demands. Furthermore, the $b_{N}$ values analyzed in this study are based on measurements of $\mathrm{N}$ excreted as dissolved ammonia $\left(\mathrm{NH}_{3}\right)$ or ammonium ions $\left(\mathrm{NH}_{4}^{+}\right)$(37.5\% and $62.5 \%$ of total measures, respectively). Analyzing nitrogen excretion in this way does not account for total $\mathrm{N}$-excretion because other nitrogen-containing waste products, such as urea, may also be released. Yet, because of the high solubility of $\mathrm{NH}_{3}$ and $\mathrm{NH}_{4}^{+}$in water, most aquatic species excrete the majority of their nitrogenous waste in these forms (Wright 1995). Indeed, $\mathrm{NH}_{3}$ and 
$\mathrm{NH}_{4}^{+}$commonly account for over $80 \%$ of the nitrogenous products excreted by zooplankton (reviewed by Bidigare 1983). However, the similar allometric relationships for $\mathrm{N}$ excretion and respiration may arise because they comprise two of a multitude of inter-related metabolic processes. The process that is limiting may ultimately define scaling relations of the other metabolic processes, regardless of whether these other processes are directly governed by surface-area exchange. A link between the body-mass scaling of a wide range of metabolic rate processes and body-shape change over ontogeny may be particularly evident in the many pelagic invertebrates that rely upon large portions of their body surface for exchange. Such scaling relationships have been found for both respiration and nitrogen excretion rates in these animals, and these processes may strongly affect the rate of other activities.

We found a significant positive correlation between $b_{N}$ and $1 / b_{L}$ across arthropod species. This relationship is most strongly driven by the relationship in copepods, which may in part relate to a wide distribution over the body of surfaces for not only osmoregulation and gas exchange (see Johnson et al. 2014), but also possibly $\mathrm{N}$ excretion (D. Weihrauch pers. comm.). We suggest that the weaker (albeit still significant) relationship in the larger and more impermeable arthropods, including amphipods, euphausiids and decapods, is consistent with SA theory, because a basic assumption of the model (that permeable surface area is directly proportional to Euclidean surface area of the body) may be less likely to apply to these animals.

Despite undertaking an extensive search for phosphorus excretion scaling data during ontogeny, we found an insufficient number of exponents $\left(b_{P}\right)$ (28 values across 10 species), thus precluding reliable comparisons to body-shape changes. Since rates of phosphorus and nitrogen excretion correlate tightly across species (Wen and Peters 1994), future analyses of $b_{P}$ values may prove useful in further evaluating the relative effects of SA and RTNs on metabolic scaling. Given that P-excretion involves different biochemical pathways than $\mathrm{N}$ excretion, the $\mathrm{O}_{2}: \mathrm{P}$ ratio may not vary in the same way as the $\mathrm{O}_{2}: \mathrm{N}$ ratio.

Predictions of metabolic scaling models are most often tested by using the rate of oxygen consumption as a proxy for metabolic rate (e.g., Brown et al. 2004). Much more rarely have such theories been tested with scaling relationships of excretion rates with body size. We found a significant positive correlation between $b_{N}$ and degree of shape change over ontogeny (as indexed by $1 / b_{L}$ ). An increase in $b_{N}$ with increasing body elongation or flattening (as indicated by $b_{L}$ values below 3) supports predictions of SA theory, while contradicting the predictions of RTN models (Figs. 2 and 3). We also show that in many pelagic invertebrates the ontogenetic body-mass scaling of N-excretion can differ from that of respiration. The associated developmental changes in $\mathrm{O}_{2}: \mathrm{N}$ ratio are hypothesized to be the result of adaptive shifts in the priority of protein and lipid use for growth, reproduction, body maintenance, and other activities. Our results call attention to the importance of testing metabolic scaling models by considering the various components of metabolism, including both the rates of oxygen consumption and the release of metabolic wastes, and the various anabolic and catabolic pathways involved in the processing of different kinds of biochemical materials, including proteins, lipids and carbohydrates (see also Glazier 2014a).

\section{References}

Banavar, J. R., M. E. Moses, J. H. Brown, J. Damuth, A. Rinaldo, R. M. Sibly, and A. Maritan. 2010. A general basis for quarter-power scaling in animals. Proc. Natl. Acad. Sci. 107: 15816-15820. doi: 10.1073/pnas.1009974107

Bidigare, R. R. 1983. Nitrogen excretion by marine zooplankton, p. 385-410. In E. J. Carpenter and D. G. Capone [eds.], Nitrogen in the marine environment. Academic Press.

Bohonak A.J., K. van der Linde. 2004. RMA: software for Reduced Major Axis regression, Java version. Website: http://www.kimvdlinde.com/professional/rma.html.

Brown, J. H., J. F. Gillooly, A. P. Allen, V. M. Savage, and G. B. West. 2004. Toward a metabolic theory of ecology. Ecology. 85: 1771-1789. doi: 10.1890/03-9000

Capuzzo, J. M., and B. A. Lancaster. 1979. Some physiological and biochemical considerations of larval development in the American lobster Homarus americanus Milne Edwards. J. Exp. Mar. Biol. Ecol. 40: 53-62. doi:10.1016/ 0022-0981(79)90033-9

Dodds, P. S. 2010. Optimal form of branching supply and collection networks. Phys. Rev. Lett. 104: 048702. doi: 10.1103/physrevlett.104.048702

Elser, J. J., and others. 2007. Global analysis of nitrogen and phosphorus limitation of primary producers in freshwater, marine and terrestrial ecosystems. Ecol. Lett. 10: 11351142. doi: 10.1111/j.1461-0248.2007.01113.x

Glazier, D. S. 2005. Beyond the '3/4-power law': Variation in the intra- and interspecific scaling of metabolic rate in animals. Biol. Rev. 80: 611-662. doi: 10.1017/s14647 93105006834

Glazier, D. S. 2014a. Metabolic scaling in complex living systems. Systems 2: 451-540. doi: 10.3390/systems2040451

Glazier, D. S. 2014b. Scaling of metabolic scaling within physical limits. Systems 2: 425-450. doi: 10.3390/systems 2040425

Glazier, D. S. 2015. Is metabolic rate a universal pacemaker for biological processes? Biol. Rev. 90: 377-407. doi: 10.1111/brv.12115

Glazier, D. S., A. G. Hirst, and D. Atkinson. 2015. Shape shifting predicts ontogenetic changes in metabolic scaling in diverse aquatic organisms. Proc. R. Soc. Lond. B Biol. Sci. 282: 20142302. doi: 10.1098/rspb.2014.2302 
Graham, J. B. 1988. Ecological and evolutionary aspects of integumentary respiration: Body size, diffusion, and the Invertebrata. Am. Zool. 28: 1031-1045. doi: 10.1093/icb/ 28.3.1031

Hessen, D. O., T. C. Jensen, M. Kyle, and J. J. Elser. 2007. RNA responses to $\mathrm{N}$-and P-limitation; reciprocal regulation of stoichiometry and growth rate in Brachionus. Funct. Ecol. 21: 956-962. doi: 10.1111/j.1365-2435. 2007.01306.X

Hill, R. W., G. A. Wyse, and M. Anderson. 2012. Animal physiology, 3rd ed. Sinauer Associates.

Hirst, A. G. 2012. Intra-specific scaling of mass to length in pelagic animals: Ontogenetic shape change and its implications. Limnol. Oceanogr. 57: 1579-1590. doi: 10.4319/ lo.2012.57.5.1579

Hirst, A. G., D. S. Glazier, and D. Atkinson. 2014. Body shape shifting during growth permits tests that distinguish between competing geometric theories of metabolic scaling. Ecol. Lett. 17: 1274-1281. doi: 10.1111/ele.12334

Ikeda, T. 1974. Nutritional ecology of marine zooplankton, p. 1-97, Memoirs of the faculty of fisheries. Hokkaido Univ.

Ikeda, T. 1985. Metabolic rates of epipelagic marine zooplankton as a function of body mass and temperature. Mar. Biol. 85: 1-11. doi: 10.1007/bf00396409

James, C., J. Fisher, and B. Moss. 2003. Nitrogen driven lakes: The Shropshire and Cheshire Meres? Arch. Hydrobiol. 158: 249-266. doi: 10.1127/0003-9136/2003/0158-0249

Johnson, K. E., L. Perreau, G. Charmantier, M. CharmantierDaures, and C. E. Lee. 2014. Without gills: Localization of osmoregulatory function in the copepod Eurytemora affinis. Physiol. Biochem. Zool. 87: 310-324. doi:10.1086/674319

Kleiber, M. 1932. Body size and metabolism. Hilgardia 6: 315-353. doi: 10.3733/hilg.v06n11p315

Kleiber, M. 1961. The fire of life. An introduction to animal energetics. John Wiley.

Mayzaud, P. 1973. Respiration and nitrogen excretion of zooplankton. II. Studies of the metabolic characteristics of starved animals. Mar. Biol. 21: 19-28. doi: 10.1007/ bf00351188

Mayzaud, P., and R. Conover. 1988. O:N atomic ratio as a tool to describe zooplankton metabolism. Mar. Ecol. Prog. Ser. 45: 289-302. doi: 10.3354/meps045289

Moore, C. M., and others. 2013. Processes and patterns of oceanic nutrient limitation. Nat. Geosci. 6: 701-710. doi: 10.1038/ngeo1765

Okie, J. G. 2013. General models for the spectra of surface area scaling strategies of cells and organisms: Fractality, geometric dissimilitude, and internalization. Am. Nat. 181: 421-439. doi: 10.1086/669150

Pawar, S., A. I. Dell, and V. M. Savage. 2012. Dimensionality of consumer search space drives trophic interaction strengths. Nature 486: 485-489. doi: 10.1038/nature11131
Pirow, R., F. Wollinger, and R. Paul. 1999. The sites of respiratory gas exchange in the planktonic crustacean Daphnia magna: An in vivo study employing blood haemoglobin as an internal oxygen probe. J. Exp. Biol. 202: 3089-3099.

Price, C. A., and others. 2012. Testing the metabolic theory of ecology. Ecol. Lett. 15: 1465-1474. doi: 10.1111/ j.1461-0248.2012.01860.x

Rubner, M. 1883. Uber den Einfluss der Korpergrosse auf Stoff- und Kraftwechsel. Z. Biol. 19: 535-562.

Savage, V. M., E. J. Deeds, and W. Fontana. 2008. Sizing up allometric scaling theory. PLoS Comput. Biol. 4: e1000171. doi: 10.1371/journal.pcbi.1000171

Schmidt-Nielsen, K. 1984. Scaling: Why is animal size so important? Cambridge Univ. Press.

van de Pol, M., and J. Wright. 2009. A simple method for distinguishing within- versus between-subject effects using mixed models. Anim. Behav. 77: 753-758.

Wen, Y. H., and R. H. Peters. 1994. Empirical models of phosphorus and nitrogen excretion rates by zooplankton. Limnol. Oceanogr. 39: 1669-1679. doi: 10.4319/1o.1994. 39.7.1669

West, G. B., J. H. Brown, and B. J. Enquist. 1997. A general model for the origin of allometric scaling laws in biology. Science 276: 122-126. doi: 10.1126/science.276.5309.122

West, G. B., J. H. Brown, and B. J. Enquist. 1999. The fourth dimension of life: Fractal geometry and allometric scaling of organisms. Science 284: 1677-1679. doi: 10.1126/ science. 284.5420 .1677

White, C. R., and M. R. Kearney. 2014. Metabolic scaling in animals: Methods, empirical results, and theoretical explanations. Compr. Physiol. 4: 231-256. doi: 10.1002/ cphy.c110049

Wright, P. A. 1995. Nitrogen excretion: Three end products, many physiological roles. J. Exp. Biol. 198: 273-281. doi: not available

\section{Acknowledgments}

AGH and MKSL were supported by the UK Natural Environment Research Council and Department for Environment, Food and Rural Affairs [grant number NE/L003279/1, Marine Ecosystems Research Programme]. Shin-Ichi Uye and Mark Jensen kindly provided data from their publications. Curtis Horne assisted with statistical analysis. We thank David Pond for comments upon an earlier version of this paper. Dirk Weihrauch provided important and insightful information on excretion. We thank the reviewers and editors for their informed comments.

\section{Conflict of Interest}

None declared.

Submitted 07 January 2016 Revised 21 May 2016; 13 July 216 Accepted 25 July 2016 Associate editor: Thomas Kiørboe 